NOTICE: This is the author's version of a work that was accepted for publication in Surface \& Coatings Technology. Changes resulting from the publishing process, such as peer review, editing, corrections, structural formatting, and other quality control mechanisms may not be reflected in this document. Changes may have been made to this work since it was submitted for publication. A definitive version was subsequently published in Surface \& Coatings Technology [205, 8-9, 2011] DOI 10.1016/j.surfcoat.2010.11.020 


\section{Accepted Manuscript}

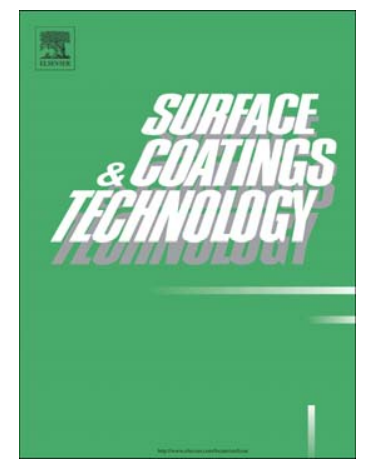

Effects of substrate curvature radius, deposition temperature and coating thickness on the residual stress field of cylindrical thermal barrier coatings

W.G. Mao, J.P. Jiang, Y.C. Zhou, C. Lu

PII:

S0257-8972(10)01176-X

DOI:

doi: $10.1016 /$ j.surfcoat.2010.11.020

Reference: $\quad$ SCT 16273

To appear in: $\quad$ Surface \& Coatings Technology

Received date: 22 April 2010

Accepted date: 8 November 2010

Please cite this article as: W.G. Mao, J.P. Jiang, Y.C. Zhou, C. Lu, Effects of substrate curvature radius, deposition temperature and coating thickness on the residual stress field of cylindrical thermal barrier coatings, Surface \& Coatings Technology (2010), doi: 10.1016/j.surfcoat.2010.11.020

This is a PDF file of an unedited manuscript that has been accepted for publication. As a service to our customers we are providing this early version of the manuscript. The manuscript will undergo copyediting, typesetting, and review of the resulting proof before it is published in its final form. Please note that during the production process errors may be discovered which could affect the content, and all legal disclaimers that apply to the journal pertain. 


\title{
Effects of substrate curvature radius, deposition temperature and coating thickness on the residual stress field of cylindrical thermal barrier coatings
}

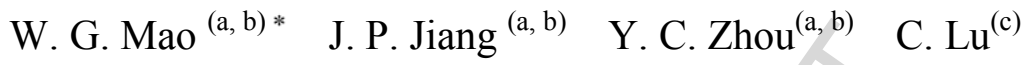 \\ (a) Key Laboratory of Low Dimensional Materials \& Application Technology, Ministry of Education, \\ Xiangtan University, Hunan 411105, China \\ (b) Aeronautical Science and Technology Key Laboratory of Aeronautical Test and Evaluation, Nanchang \\ Hangkong University, Nanchang 330063, China \\ ${ }^{(c)}$ Department of Mechanical Engineering, Curtin University, Perth, Western Australia 6845, Australia
}

\begin{abstract}
In a thermal barrier coating (TBC) system with cylindrical geometry, the position of coating plays an important role in the distribution of residual stress. In this paper, the residual stress field in three different types of TBCs with cylindrical geometry has been analyzed. The main focus is on the effects of substrate curvature radius, deposition temperature and coating thickness on the residual stress distribution during a deposition process. The results show that the substrate curvature radius significantly affects the distributions of radial and hoop residual stresses, which are in good agreement with experimental measurements by photo-stimulated luminescence piezospectroscopy (Wang et al., Acta Mater., 2009, 57(1):182-195). The maximum radial residual stress locates closely to the coating/thermal grown oxide interface. However, the maximum hoop residual stress lies in the thermal grown oxide layer, which is much more than other three layers and presents a strong stress singularity along the thickness direction.
\end{abstract}

Keywords: thermal barrier coatings; residual stress; curvature radius, coating position

\footnotetext{
* Corresponding author: W. G. Mao, Faculty of Materials, Optoelectronics and Physics, Xiangtan University, Hunan 411105, China. Fax: +86-731-58292468, Tel: +86-731-58298580, Email: ssamao@xtu.edu.cn.
} 


\section{Introduction}

Thermal barrier coatings (TBCs) have been a common method to provide the thermal resistance for gas turbine engines and other high temperature components, which can greatly increase their durability and the fuel efficiency $[1,2]$. A TBC system usually consists of ceramic coating, thermally grown oxide (TGO), bond coat (BC) and substrate. In service, residual stresses gradually generate and accumulate due to the mismatch of material properties, which may eventually cause interface crack propagation and coating spallation [1-3]. Thus, the evolution of residual stress plays an important role in predicting the life of TBCs. In the past decade, many engineering methods have been developed to evaluate the evolution of residual stress in different types of TBCs, such as X-ray diffraction [4-8], Raman spectroscopy [9-12], substrate removal [13], curvature measurement $[14,15]$, photo-stimulated luminescence piezospectroscopy (PLPS) [16-19] and indentation methods [20-24]. At the same time, researchers have proposed the different forms of analytical solutions to evaluate the stress distribution of multilayer systems. The earliest analytical model for the elastic thermal stress in a bilayer system was derived by Timoshenko [25] based on the classical bending theory. Timoshenko's approach has been widely adopted by others to analyze the thermal residual stress in TBCs [26-33]. In these theoretical works, the consideration is focused on the effects of material properties (mainly, the elastic modulus of bond coat), coating thickness, heat conduction coefficients, interface asperity and temperature gradient on the distribution of residual stress in TBCs during deposition or thermal cycling. However, the coatings are usually deposited on substrates with different geometrical shapes, e.g., the turbine blade and vane in aircraft engine. The evolution of thermal/residual stress of coating located in the concave positions of the curved substrate may be significantly different from that in the convex positions. Hutchinson et al. pointed out that the concavity and convexity characteristic of substrate in multilayer TBCs would influence the residual stress distribution, and they would profoundly affect the energy release rates of the interface delamination and crack 
propagation path during spallation [34,35]. Qasim et al. investigated the influence of complex geometry on contact damage in a curved brittle coating and substrate system. They found that the local surface curvature plays an important role in the initiation and propagation of radial cracks and fracture behavior in brittle coating [36]. Thus, it is necessary to study the effects of coating located in different concave and convex positions of the curved substrate on the distribution of residual stress in TBCs. On the basis of our recent work [37, 38], an analytical solution of a four-concentric-hollow cylinder model is deduced [39]. In this paper, considering three different types of TBCs with cylindrical geometry, our attention will focus on the effects of substrate curvature radius, deposition temperature and coating thickness on the distribution of residual stresses. It is expected that some valuable conclusions can be obtained for predicting the residual stress distribution of TBCs and promoting their durability.

\section{Analytical modeling}

For a long cylindrical TBC, a three-dimensional stress-strain problem can be reduced to a two-dimensional plane strain problem. Figure 1 schematically shows three different structures of TBCs: coating located in the convex position (type A1), coating located in the concave position (type A2), and coating deposited in both convex and concave positions of the curved substrate (type A3). The representative positions, $A, B, C, D, E$ and $F$ denote the different inner or outer surfaces in type $\mathrm{A} 1, \mathrm{~A} 2$ and $\mathrm{A} 3 \mathrm{TBC}$ models, and $R_{1}$ represents the curvature radius of inner surface of substrate. Here, let us first consider the case of type A1, which consists of substrate, bond coat, TGO and ceramic coating layer from the inner to outer surfaces along the radius direction (see Fig. 1(a)). The TBC system is assumed to be stress free at deposition temperature $T_{1}$ and the original curvature radius of each layer is $R_{j}(j=1,2, \ldots, 5)$. After cooling to ambient temperature, the contracted curvature radius of each layer is defined as $r_{j}(j=1,2, \ldots$, 
5), respectively. Given that each layer is unconstrained, it can individually deform on cooling. For example, substrate changes from the original configuration to a middle configuration, as shown in Figs. 2(a) and (b). There is no residual stress occurred at this stage. The radii $a_{1}$ and $a_{2}$ along the radial displacement direction can be obtained by

$$
\begin{aligned}
& a_{1}=R_{1} 1+\alpha_{s} \Delta \mathrm{T} \\
& a_{2}=R_{2} \quad 1+\alpha_{s} \Delta \mathrm{T}
\end{aligned}
$$

where $\alpha_{s}$ is the thermal expansion coefficient of substrate and $\Delta T$ is the temperature change. To be consistent with the actual configuration of a type A1 TBC system after cooling, an external pressure $P_{1}$ is assumed to be applied on the outer surface of substrate. It is noted that the applied internal pressure is zero because there is no radial pressure on the internal surface of substrate. The deformation of substrate changes from the middle configuration $\left(a_{1}, a_{2}\right)$ to the actual configuration $\left(r_{1}, r_{2}\right)$. The residual radial stress $\sigma_{i, r}$ and hoop stress $\sigma_{i, \theta \theta}$ in substrate can be calculated by solving Lame equations [39],

$$
\begin{gathered}
\sigma_{s, r r}=-\frac{a_{2}^{2} P_{1}}{a_{2}^{2}-a_{1}^{2}}\left(1-\frac{a_{1}^{2}}{r^{2}}\right) \\
\sigma_{s, \theta \theta}=-\frac{a_{2}^{2} P_{1}}{a_{2}^{2}-a_{1}^{2}}\left(1+\frac{a_{1}^{2}}{r^{2}}\right)
\end{gathered}
$$

where subscript $s$ refers to substrate. Thus, in the plane strain state, the radial strain $\varepsilon_{s, r r}$ and hoop strain $\varepsilon_{s, \theta \theta}$ in substrate can be deduced to, respectively,

$$
\begin{gathered}
\varepsilon_{s, r r}=\frac{1-\mu_{s}^{2}}{E_{s}}\left(\sigma_{s, r r}-\frac{\mu_{s}}{1-\mu_{s}} \sigma_{s, \theta \theta}\right) \\
\varepsilon_{s, \theta \theta}=\frac{1-\mu_{s}^{2}}{E_{s}}\left(\sigma_{s, \theta \theta}-\frac{\mu_{s}}{1-\mu_{s}} \sigma_{s, r r}\right)
\end{gathered}
$$

where $E_{s}$ and $\mu_{s}$ denote Young's modulus and Poisson ratio of substrate. Combining Eqs. (3), 
(4) with (6), hoop strains at the surfaces of substrate are

$$
\begin{aligned}
& \left.\varepsilon_{s, \theta \theta}\right|_{r=a_{1}}=\frac{21-\mu_{s}^{2}}{E_{s}} \cdot \frac{a_{2}^{2} P_{1}}{a_{2}^{2}-a_{1}^{2}} \\
& \left.\varepsilon_{s, \theta \theta}\right|_{r=a_{2}}=-\frac{P_{1} 1+\mu_{s}\left[1-2 \mu_{s} a_{2}^{2}+a_{1}^{2}\right]}{E_{s} a_{2}^{2}-a_{1}^{2}}
\end{aligned}
$$

The residual stress and strain in other three layers of the type A1 TBC can be obtained by the similar method (see Appendix A). The interface continuities of radial displacements must be maintained when the whole cylindrical TBC system is cooled from deposition temperature $T_{1}$ to room temperature $T_{o}$. These continuity conditions can be expressed as follows by combining Eqs. (7), (8) with (A13-A26),

$$
\begin{aligned}
& \frac{r_{1}}{a_{1}}-1=\frac{21-\mu_{s}^{2}}{E_{s}} \cdot \frac{a_{2}^{2} P_{1}}{a_{2}^{2}-a_{1}^{2}} \\
& \frac{r_{2}}{a_{2}}-1=-\frac{P_{1} 1+\mu_{s}\left[1-2 \mu_{s} a_{2}^{2}+a_{1}^{2}\right]}{E_{s} a_{2}^{2}-a_{1}^{2}} \\
& \frac{r_{2}}{b_{1}}-1=\frac{P_{1} 1+\mu_{b}\left[\begin{array}{cc}
1-2 \mu_{b} & b_{1}^{2}+b_{2}^{2}
\end{array}\right]-21-\mu_{b}^{2} b_{2}^{2} P_{2}}{E_{b} b_{2}^{2}-b_{1}^{2}} \\
& \frac{r_{3}}{b_{2}}-1=-\frac{P_{2} 1+\mu_{b}{ }_{1}\left[1-2 \mu_{b} b_{2}^{2}+b_{1}^{2}\right]-21-\mu_{b}^{2} b_{1}^{2} P_{1}}{E_{b} b_{2}^{2}-b_{1}^{2}}
\end{aligned}
$$

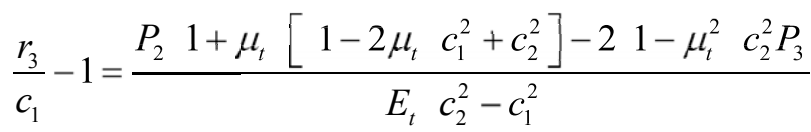

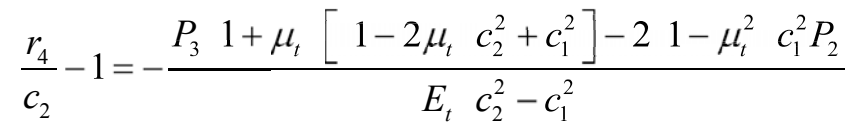

$$
\begin{aligned}
& \frac{r_{4}}{d_{1}}-1=\frac{P_{3} 1+\mu_{c}\left[\begin{array}{cc}
1-2 \mu_{c} & d_{1}^{2}+d_{2}^{2}
\end{array}\right]}{E_{c} d_{2}^{2}-d_{1}^{2}}
\end{aligned}
$$




$$
\frac{r_{5}}{d_{2}}-1=\frac{21-\mu_{c}^{2} d_{1}^{2} P_{3}}{E_{c} d_{2}^{2}-d_{1}^{2}}
$$

where $b_{k}, c_{k}$, and $d_{k}(k=1,2)$ are the changed inner and outer radii of bond coat, TGO and ceramic coating layer at the middle configuration. The subscripts $b, t$ and $c$ refer to bond coat, TGO and coating, respectively. $\alpha_{b}, \alpha_{t}$ and $\alpha_{c}$ are thermal expansion coefficients, $E_{b}, E_{t}$ and $E_{c}$ are Young's moduli, $\mu_{b}, \mu_{t}$ and $\mu_{c}$ are Poisson ratios, and $P_{j}(j=1,2,3)$ indicates the applied pressure on the substrate/bond coat, bond coat/TGO, and TGO/TBC interfaces, respectively.

If the material properties of each layer and their original radii are given, the solutions of $P_{1}$, $P_{2}, P_{3}$ and $r_{j}(j=1,2, \ldots, 5)$ can be obtained by Eqs. (9-16). Then, substituting these solutions into Eqs. (3), (4) and (A7-A12), the residual radial stress $\sigma_{i, r}$ and hoop stress $\sigma_{i, \theta \theta}$ of a whole TBC system can be determined. Similarly, for the other two types of structures (i.e., A2 and A3) in Fig. 1, their residual stress fields in TBCs can be deduced using the same method.

\section{Results and discussion}

\subsection{Effect of substrate curvature radius on residual stress}

The material properties of a TBC system used in calculations are listed in Table 1 [40]. For simplification, these material properties are temperature-independent. The original values of the thickness of substrate, bond coat, TGO and top coating are $h_{s}=2000 \mu \mathrm{m}, h_{b}=100 \mu \mathrm{m}, h_{t}=1 \mu \mathrm{m}$ and $h_{c}=300 \mu \mathrm{m}$. The corresponding substrate curvature radius $R_{1}$ is assumed to be $2,4,6,8$ and $10 \mathrm{~mm}$, respectively. It is also assumed that $T_{1}=600{ }^{\circ} \mathrm{C}$ and $T_{o}=20{ }^{\circ} \mathrm{C}$. As shown in Fig. 3(a), radial stresses in all layers are tensile when the system is cooled down from $T_{1}$ to $T_{o}$. This is attributed to the lower thermal expansion coefficients of bond coat and ceramic coating compared to substrate. The radial stresses at positions $A$ and $B$ are equal to zero, which is 
consistent with the actual TBC configuration because there is no pressure applied on these two surfaces. The maximum residual radial stress locates within the convex coating closely to the coating/TGO interface and its value decreases from 23 to $8 \mathrm{MPa}$ when $R_{1}$ changes from 2 to 10 $\mathrm{mm}$. That is, the maximum tensile radial stress would increase by about $65 \%$ when the substrate curvature $\left(1 / R_{1}\right)$ increases by a factor of 4 . As shown in Fig. 3(b), the variation of $R_{1}$ has a little influence on the distribution of hoop stress. The hoop stress in substrate is tensile but compressive in bond coat, TGO and ceramic coating. The stress distribution is similar to that obtained by Zhang et al. [32]. The hoop stress in TGO is $-2.25 \mathrm{GPa}$, which is much larger than that in the bond coat and coating due to the stress singularity in TGO and stress discontinuity in TBCs along the thickness direction. The similar results are also found on residual stress in a duplex TBC system $[5,27,28,38]$. In order to improve the life and durability of TBCs, a lot of studies have been done by using functionally gradient materials instead of bond coat to reduce stress singularity and stress gradient discontinuity in TBCs [41-47]. The analysis of residual stress indicates that the stress singularity in a functionally gradient material system gradually vanishes and a continuous stress gradient varies from the coating surface to the coating/substrate interface $[32,48]$.

In the case of type A2 TBCs shown in Fig. 4(a), it is found that radial stresses in all TBC layers are compressive after cooling from $T_{1}$ to $T_{o}$. The maximum compressive radial stress locates within the concave coating closely to the coating/TGO interface. The absolute values of maximum radial residual stresses also decrease with the increase of $R_{1}$, which is similar to that in type $\mathrm{A} 1$. It changes from -50 to $-10 \mathrm{MPa}$ when $R_{1}$ increases from 2 to $10 \mathrm{~mm}$. The compressive radial stress may quickly diminish as the curvature radius increases. The hoop stresses as a function of $R_{1}$ are shown in Fig. 4(b). The variation of $R_{1}$ influences the distribution of hoop stresses. The hoop stress in substrate is tensile but compressive in bond coat, 
TGO and ceramic coating due to the mismatch of material properties. The maximum hoop stress locates in the TGO layer and is equal to $-2.24 \mathrm{GPa}$. The compressive radial stress of each layer is much less compared to its hoop stress, which is in good agreement with the available results [16, 32].

In type A3 TBCs shown in Fig. 5, it is of interest to see that the distribution of residual stresses in the convex and concave regions is similar to that of type A1 and A2 TBC systems. That is, residual stress in type $\mathrm{A} 3 \mathrm{TBCs}$ can be approximately regarded as a superimposition of that in type A1 and A2 TBCs due to only considering thermal elastic deformation. The average hoop stresses in the convex and concave coating positions of the type A3 TBC system are -242.7 and -260.4 MPa, respectively, as shown in Fig. 5(b). The average hoop stresses of top coating are -247.9 and $-272.8 \mathrm{MPa}$ for type A1 and A2 TBC systems, respectively, see Figs. 3(b) and 4(b). The slight difference among these results may be due to the different geometrical structures and the mismatch of material properties.

As is known, the residual stress in TGO controls the location and rate of spallation [2]. The TGO stress can be from 1 to $5 \mathrm{GPa}$, much more than 0.2 to $0.5 \mathrm{GPa}$ in other three layers[16, 18 , 19]. The evolution of residual stress in TGO closely to the coating/TGO interface is a function of $R_{1}$ as plotted in Fig 6. It can be seen that radial residual stresses in type A1 and A2 are consistent well with that in the convex and concave locations of the type A3, respectively. The stress in convex positions is tensile and changes from 10 to $20 \mathrm{MPa}$. Based on the recent work by Wang et al. [16], a three-dimensional residual stress state in the TGO of a TBC blade measured by using PLPS reveals a tensile radial stress being associated with a convex curvature. The tensile stress is $50 \mathrm{MPa}$ when the curvature radius is $0.5 \mathrm{~mm}$ and it can go up to approximately $150 \mathrm{MPa}$ when the curvature radius is $0.1 \mathrm{~mm}$. However, the radial stress becomes very small, about several to $25 \mathrm{MPa}$ when the curvature radius exceeds to $2 \mathrm{~mm}$ [16]. Our results agree well with that by 
PLPS measurements [16]. The compressive radial stress in the concave position varies from -45 to $-10 \mathrm{MPa}$ when $R_{1}$ increases from 2 to $10 \mathrm{~mm}$. The influence of $R_{1}$ on the radial stress distribution in concave position is larger than that in the convex location. However, $R_{1}$ plays an important role in the distribution of residual hoop stress for different types of TBCs, as shown in Fig. 6(b). The magnitude of hoop stress in the concave position of type A3 is 60 to $80 \mathrm{MPa}$, which is smaller than that in the concave position of type A2. Similarly, the value of hoop stress in the convex position of type $\mathrm{A} 3$ is 60 to $70 \mathrm{MPa}$, which is also smaller than that in the convex position of type A1. In Wang's PLPS measurements, they found out that the stress level of TGO is independent of the curvature of a blade surface [16]. The relative contribution of the two stress levels appears to be correlated with the $\theta-\mathrm{Al}_{2} \mathrm{O}_{3}$ content of TGO, which is dependent on the position on the blade [16]. Here, the analytical results are similar to their experimental measurements.

\subsection{Effect of deposition temperature on residual stress}

As shown in Fig. 7(a), radial stresses in type A1 TBCs are tensile and their values are proportional to deposition temperature $T_{1}$. The maximum radial stress locates within the convex coating at the coating/TGO interface and its value is from 8.0 to $23.5 \mathrm{MPa}$ as $T_{1}$ increases from 400 to $1000{ }^{\circ} \mathrm{C}$. The magnitude of radial residual stress on the ceramic coating surface is 11.4 MPa when $T_{1}$ is $600{ }^{\circ} \mathrm{C}$, which is consistent with the results by Teixeira et al. [4]. The hoop stresses also increase with the increase of $T_{1}$ (see Fig. 7(b)). The hoop stress in substrate is tensile, but compressive in the bond coat, TGO and ceramic coating due to the mismatch of material properties. Especially, the average hoop residual stress in ceramic coating changes from -110 to $-400 \mathrm{MPa}$ as $T_{1}$ varies from 400 to $1000{ }^{\circ} \mathrm{C}$, which is coincident with the available results $[4,49,50]$. It is obvious that $T_{1}$ strongly affects the distribution of hoop residual stress in 
the ceramic coating. It would be a challenge on how to control a reasonable deposition temperature range during the $\mathrm{TBC}$ preparation in order to obtain an ideal residual stress distribution.

For type A2 TBCs shown in Fig. 8(a), radial stresses are compressive and their absolute values gradually increase with the increase of $T_{1}$, which is similar to that in type A1 TBCs. The maximum of the compressive radial stress still locates within the concave coating near the coating/TGO interface, and its value changes from -12 to $-35 \mathrm{MPa}$ when $T_{1}$ changes from 400 to $1000{ }^{\circ} \mathrm{C}$. The hoop stress in type $\mathrm{A} 2 \mathrm{TBCs}$ is also proportional to $T_{1}$. The hoop stress in substrate is tensile but compressive in the bond coat, TGO and ceramic coating (see Fig. 8(b)). The hoop stress in TGO ranges from -1.4 to $-3.7 \mathrm{GPa}$ as $T_{1}$ increases from 400 to $1000{ }^{\circ} \mathrm{C}$, which agrees with the order of residual stress in TGO for as-received air plasma sprayed TBCs [5, $16,38]$.

The distribution of residual stresses in the convex and concave regions of the type A3 TBCs is similar to that of the type A1 and A2 TBCs, as shown in Fig. 9. The residual radial and hoop stresses increase with the increase of $T_{1}$. The radial stress is equal to zero at positions $E$ and $F$, which is consistent with that expected in an actual TBCs configuration. The radial stress is tensile within the convex region and becomes compressive in the concave region. The distribution of residual hoop stress in a type A3 system is approximately symmetrical. The hoop stress in TGO increases rapidly from -1.5 to $-4.0 \mathrm{GPa}$ when $T_{1}$ changes from 400 to $1000{ }^{\circ} \mathrm{C}$, as shown in Figs. 9(b). The high level of hoop residual stress in TGO of the TBC blade measured by Wang et al. is about $-4.0 \mathrm{GPa}$ [16]. Gell et al. also studied the evolution of residual stress in TGO and concluded that the residual stress variation is from -2.5 to $-4.0 \mathrm{GPa}[18,19]$. Our analysis is consistent well with these experimental results.

To evaluate the effect of $T_{1}$ on the variation of residual stress in TGO, the residual stress is 
extracted and shown in Fig. 10 as a function of $T_{1}$. It is found that the radial stress is tensile when coating locates in the convex positions of substrate. It increases linearly from 5 to $18 \mathrm{MPa}$ as $T_{1}$ changes from 400 to $1000{ }^{\circ} \mathrm{C}$. However, it becomes compressive in the concave coating of substrate. Its value increases linearly from -10 to $-29 \mathrm{MPa}$ when $T_{1}$ changes from 400 to 1000 ${ }^{\circ} \mathrm{C}$. This indicates that the radial residual stress is closely related to the coating position in a cylindrical TBC system. In addition, it is noted that the hoop stresses in TGO are compressive and increase linearly from -1.5 to $-3.9 \mathrm{GPa}$ when $T_{1}$ changes from 400 to $1000{ }^{\circ} \mathrm{C}$. But it is independent of the coating positions (see Fig. 10(b)). In this case, the effect of $T_{1}$ is clearly different from the influence of $R_{1}$ on the residual hoop stress in TGO (see Fig. 6(b)).

\subsection{Effect of coating thickness on residual stress}

As shown in Fig. 11(a), radial stresses in TBC layers are tensile and increase with the increase of $h_{c}$. The maximum radial stress locates within coating around the coating/TGO interface and its value changes from 5 to $24 \mathrm{MPa}$ as $h_{c}$ increases from 100 to $600 \mu \mathrm{m}$. With the increase of $h_{c}$, hoop stresses in bond coat, TGO and ceramic coating decrease, but increase in substrate, as shown in Fig. 11(b). The results indicate that the hoop stress in coating is several times more than its radial stress, although their amplitudes are nearly equivalent under the same value of $h_{c}$. Zhang et al. studied the influence of coating thickness on residual stress in as-sprayed FGM TBCs [32]. It is found that the distribution of residual stress of the duplex TBC system in the current work is similar to their results.

For a type $\mathrm{A} 2 \mathrm{TBC}$ system, radial stresses in all layers are compressive and increase with the increase of $h_{c}$ (see Fig. 12(a)). The maximum compressive radial stress locates in the concave coating closely to the coating/TGO interface, which varies from -14 to $-36 \mathrm{MPa}$ when $h_{c}$ 
increases from 100 to $600 \mu \mathrm{m}$. As $h_{c}$ increases, hoop stresses decrease in bond coat, TGO and ceramic coating, but increase in substrate (see Fig. 12(b)), which is similar to that in type A1 TBCs. The hoop stress in bond coat is in the range of -200 to $-100 \mathrm{MPa}$ as $h_{c}$ increases from 100 to $600 \mu \mathrm{m}$, which coincides with the results [49].

As shown in Fig. 13, the maximum radial stress for a type A3 system is proportional to the increase of $h_{c}$. The radial stress is zero at both positions of $E$ and $F$. The radial stress in concave position is compressive, which gradually decreases and becomes tensile in the convex position along the thickness direction. The distribution of the hoop residual stress is approximately symmetrical, which is similar to the influence of $T_{1}$ on the hoop residual stress (see Fig. 9(b)). It is obvious that there is also a large stress singularity and stress discontinuity in TGO (see Fig. 13(b)). In our earlier work, the similar stress discontinuity in duplex TBCs with planar geometry was discovered [38]. That is, the generation and accumulation of thermal/residual stress in all types of duplex TBCs are inevitable due to the mismatch of material properties and the irreversible deformation in service. To validly control the residual stress in ceramic coating, the coating thickness should remain as thin as possible.

The evolution of radial stress in both TGO layers in convex and concave positions of type A3 is almost identical to that in type A1 and A2, respectively, as shown in Fig. 14(a). Radial stress is tensile in the convex region and compressive in the concave regime. Their values increase as $h_{c}$ increases. However, Fig. 14(b) shows that hoop residual stress in TGO of three types of TBC systems decrease with the increase of $h_{c}$. The average hoop residual stress changes from -2.2 to $-2.1 \mathrm{GPa}$ when $h_{c}$ increases from 100 to $600 \mu \mathrm{m}$.

\section{Conclusions}

It is widely believed that residual stresses generated during the deposition of coatings act as 
pre-existing stresses and adversely affect the coatings' performance in service. In this paper, the distributions of residual stresses in three different types of cylindrical TBC systems during the deposition process have been discussed. The main conclusions can be summarized as follows:

(1) The sprayed ceramic coating position strongly influences the distribution and magnitude of residual stress in TBCs with cylindrical geometry. Under thermal elastic deformation, residual stress in type A3 TBCs can be approximately regarded as a superimposition of that in type A1 and $\mathrm{A} 2$ TBCs.

(2) For a same type of TBC system, substrate curvature radius plays an important role in the evolution of residual stress. The maximum tensile radial stress would increase by about $65 \%$ when substrate curvature increases by a factor of 4 . Hoop stress gradually increases as substrate curvature radius increases.

(3) Residual stresses in all layers of three types of structures would increase as deposition temperature and coating thickness increase. Therefore, to obtain a reasonable stress state in as-received TBCs, the deposition temperature and coating thickness are suggested to be as small as possible.

\section{Acknowledgements}

This work has been supported by the Open Fund of Aeronautical Science and Technology

Key Lab. of Aeronautical Test and Evaluation of Nanchang Hangkong University (No. HK2009005), the Fund for Young Scholars in Hunan Province (No. 08B084), the Young Teacher Fund of Ministry of Education (No. 200805301023), and the National Natural Science Foundation of China (No. 10828205). 


\section{Appendix A}

The changed inner and outer radii of other three layers in the middle configuration are defined as follows, respectively,

$$
\begin{aligned}
& b_{1}=R_{2} 1+\alpha_{b} \Delta \mathrm{T} \\
& b_{2}=R_{3} 1+\alpha_{b} \Delta \mathrm{T} \\
& c_{1}=R_{3} 1+\alpha_{t} \Delta \mathrm{T} \\
& c_{2}=R_{4} 1+\alpha_{t} \Delta \mathrm{T} \\
& d_{1}=R_{4} \quad 1+\alpha_{c} \Delta \mathrm{T} \\
& d_{2}=R_{5} \quad 1+\alpha_{c} \Delta \mathrm{T}
\end{aligned}
$$

Similarly, the different uniform pressures are applied on the inner and outer surfaces of these three layers to match the actual configurations of cylindrical TBCs. The bond coat is subjected to a uniform internal pressure $P_{1}$ at $r=r_{2}$ and an external pressure $P_{2}$ at $r=r_{3}$. TGO is subjected to a uniform internal pressure $P_{2}$ at $r=r_{3}$ and an external pressure $P_{3}$ at $r=r_{4}$. However, the coating is only subjected to an internal pressure $P_{3}$ at $r=r_{4}$. The residual radial stress $\sigma_{i, r}$ and hoop stress $\sigma_{i, \theta \theta}$ of other layers can be obtained by extending Lame equations,

$$
\begin{aligned}
& \sigma_{b, r r}=\frac{b_{1}^{2} b_{2}^{2}}{b_{2}^{2}-b_{1}^{2}} \cdot \frac{P_{2}-P_{1}}{r^{2}}+\frac{b_{1}^{2} P_{1}-b_{2}^{2} P_{2}}{b_{2}^{2}-b_{1}^{2}} \\
& \sigma_{b, \theta \theta}=-\frac{b_{1}^{2} b_{2}^{2}}{b_{2}^{2}-b_{1}^{2}} \cdot \frac{P_{2}-P_{1}}{r^{2}}+\frac{b_{1}^{2} P_{1}-b_{2}^{2} P_{2}}{b_{2}^{2}-b_{1}^{2}} \\
& \sigma_{t, r r}=\frac{c_{1}^{2} c_{2}^{2}}{c_{2}^{2}-c_{1}^{2}} \cdot \frac{P_{3}-P_{2}}{r^{2}}+\frac{c_{1}^{2} P_{2}-c_{2}^{2} P_{3}}{c_{2}^{2}-c_{1}^{2}} \\
& \sigma_{t, \theta \theta}=-\frac{c_{1}^{2} c_{2}^{2}}{c_{2}^{2}-c_{1}^{2}} \cdot \frac{P_{3}-P_{2}}{r^{2}}+\frac{c_{1}^{2} P_{2}-c_{2}^{2} P_{3}}{c_{2}^{2}-c_{1}^{2}}
\end{aligned}
$$




$$
\begin{gathered}
\sigma_{c, r r}=\frac{d_{1}^{2} P_{3}}{d_{2}^{2}-d_{1}^{2}}\left(1-\frac{d_{2}^{2}}{r^{2}}\right) \\
\sigma_{c, \theta \theta}=\frac{d_{1}^{2} P_{3}}{d_{2}^{2}-d_{1}^{2}}\left(1+\frac{d_{2}^{2}}{r^{2}}\right)
\end{gathered}
$$

where subscripts $b, t$ and $c$ refer to bond coat, TGO and ceramic coating, respectively. Similarly, the hoop strain of each layer at different interfaces can be obtained by the stress-strain relationship,

$$
\begin{aligned}
& \left.\varepsilon_{b, \theta \theta}\right|_{r=b_{1}}=\frac{P_{1} 1+\mu_{b}\left[1-2 \mu_{b} b_{1}^{2}+b_{2}^{2}\right]-21-\mu_{b}^{2} b_{2}^{2} P_{2}}{E_{b} b_{2}^{2}-b_{1}^{2}}
\end{aligned}
$$

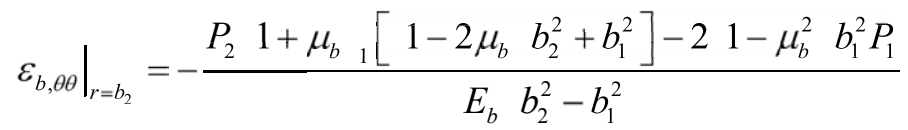

$$
\begin{aligned}
& \left.\varepsilon_{t, \theta \theta}\right|_{r=c_{1}}=\frac{P_{2} 1+\mu_{t}\left[1-2 \mu_{t} c_{1}^{2}+c_{2}^{2}\right]-21-\mu_{t}^{2} c_{2}^{2} P_{3}}{E_{t} c_{2}^{2}-c_{1}^{2}}
\end{aligned}
$$

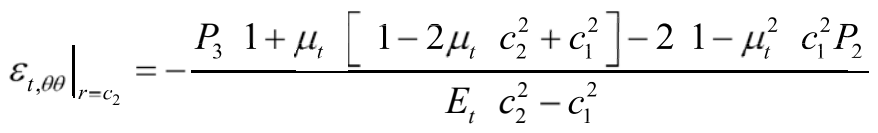

$$
\begin{aligned}
& \left.\varepsilon_{c, \theta \theta}\right|_{r=d_{1}}=\frac{P_{3} 1+\mu_{c}\left[1-2 \mu_{c} d_{1}^{2}+d_{2}^{2}\right]}{E_{c} d_{2}^{2}-d_{1}^{2}} \\
& \left.\varepsilon_{c, \theta \theta}\right|_{r=d_{2}}=\frac{21-\mu_{c}^{2} d_{1}^{2} P_{3}}{E_{c} d_{2}^{2}-d_{1}^{2}}
\end{aligned}
$$

where $E_{b}, E_{t}$ and $E_{c}$ denote Young's moduli of bond coat, TGO and coating, respectively. $\mu_{b}, \mu_{t}$ and $\mu_{c}$ are their Poisson ratios. On the other hand, hoop strains of each layer at different interfaces can be obtained by the strain definition,

$$
\begin{aligned}
& \left.\varepsilon_{s, \theta \theta}\right|_{r=a_{1}}=\frac{2 \pi r_{1}-2 \pi a_{1}}{2 \pi a_{1}}=\frac{r_{1}}{a_{1}}-1 \\
& \left.\varepsilon_{s, \theta \theta}\right|_{r=a_{2}}=\frac{r_{2}}{a_{2}}-1
\end{aligned}
$$




$$
\begin{aligned}
& \left.\varepsilon_{b, \theta \theta}\right|_{r=b_{1}}=\frac{r_{2}}{b_{1}}-1 \\
& \left.\varepsilon_{b, \theta \theta}\right|_{r=b_{2}}=\frac{r_{3}}{b_{2}}-1 \\
& \left.\varepsilon_{t, \theta \theta}\right|_{r=c_{1}}=\frac{r_{3}}{c_{1}}-1 \\
& \left.\varepsilon_{t, \theta \theta}\right|_{r=c_{2}}=\frac{r_{4}}{c_{2}}-1 \\
& \left.\varepsilon_{c, \theta \theta}\right|_{r=d_{1}}=\frac{r_{4}}{d_{1}}-1 \\
& \left.\varepsilon_{c, \theta \theta}\right|_{r=d_{2}}=\frac{r_{5}}{d_{2}}-1
\end{aligned}
$$

The continuity conditions of hoop strain at the interfaces of multilayer TBCs should be satisfied. That is, Eqs. (7), (8) and (A13-A18) must be equal to Eqs. (A19-A26), respectively. Then, Eqs. (9-16) can be obtained.

\section{References}

[1] A.G. Evans, D.R. Mumm, J.W. Hutchinson, G.H. Meier, F.S. Pettit, Prog. Mater. Sci., 46 (2001) 505-553.

[2] N.P. Padture, M. Gell, E.H. Jordan, Sci., 296 (2002) 280-284.

[3] J.L. Beuth, S.H. Narayan, Inter. J. Solids Struct., 33 (1996) 65-78.

[4] V. Teixeira, M. Andritschky, W. Fischer, H.P. Buchkremer, D. Stover, Surf. Coat. Tech., 121 (1999) 103-111.

[5] C.M. Weyant, J. Almer, K.T. Faber, Acta Mater., 58 (2010) 943-951.

[6] J. Thornton, D. Cookson, E. Pescott, Surf. Coat. Tech., 121 (1999) 96-102.

[7] D.W. Jordan, K.T. Faber, Thin Solid Films, 235 (1993) 137-141.

[8] Q. Chen, W.G. Mao, Y.C. Zhou, C. Lu, Appl. Surf. Sci., 256 (2010) 7311-7315. 
[9] M. Tanaka, M. Hasegawa, A.F. Dericioglu, Y. Kagawa, Materials Science and Engineering: A, 419 (2006) 262-268.

[10] W.G. Mao, Q. Chen, C.Y. Dai, L. Yang, Y.C. Zhou, C. Lu, Surf. Coat. Tech., 204 (2010) 3573-3577.

[11] M. Tanaka, R. Kitazawa, T. Tomimatsu, Y.F. Liu, Y. Kagawa, Surf. Coat. Tech., 204 (2009) 657-660.

[12] A. Gil, D. Naumenko, R. Vassen, J. Toscano, M. Subanovic, L. Singheiser, W.J. Quadakkers, Surf. Coat. Tech., 204 (2009) 531-538.

[13] C.R.C. Lima, J. Nin, J.M. Guilemany, Surf. Coat. Tech., 200 (2006) 5963-5972.

[14] C.H. Hsueh, E.R. Fuller, Mat Sci Eng a-Struct, 283 (2000) 46-55.

[15] S.C. Gill, T.W. Clyne, Thin Solid Films, 250 (1994) 172-180.

[16] X. Wang, G. Lee, A. Atkinson, Acta Mater., 57 (2009) 182-195.

[17] B.W. Kempshall, Y.H. Sohn, S.K. Jha, S. Laxman, R.R. Vanfleet, J. Kimmel, Thin Solid Films, 466 (2004) 128-136.

[18] M. Gell, S. Sridharan, M. Wen, E.H. Jordan, Inter. J. Appl. Ceram. Tech., 1 (2004) 316-329.

[19] M. Wen, E.H. Jordan, M. Gell, Mater. Sci. Eng. A, 398 (2005) 99-107.

[20] M. Eskner, R. Sandstrom, Surf. Coat. Tech., 177 (2004) 165-171.

[21] J. Yan, A.M. Karlsson, M. Bartsch, X. Chen, Comput. Mater. Sci., 44 (2009) 1178-1191.

[22] N. Zotov, M. Bartsch, G. Eggeler, Surf. Coat. Tech., 203 (2009) 2064-2072.

[23] A. Rico, J. Gomez-Garcia, C.J. Munez, P. Poza, V. Utrilla, Surf. Coat. Tech., 203 (2009) 2307-2314.

[24] M. Zhao, X. Chen, J. Yan, A.M. Karlsson, Acta Mater., 54 (2006) 2823-2832.

[25] S. Timoshenko, J. Opt. Soc. Am., 11 (1925) 233-255.

[26] Y.C. Tsui, T.W. Clyne, Thin Solid Films, 306 (1997) 23-33.

[27] Y.C. Tsui, T.W. Clyne, Thin Solid Films, 306 (1997) 34-51. 
[28] C.H. Hsueh, E.R. Fuller, Scripta Mater., 42 (2000) 781-787.

[29] S.Q. Nusier, G.M. Newaz, Z.A. Chaudhury, Inter. J. Solids Struct., 37 (2000) 2495-2506.

[30] X.C. Zhang, B.S. Xu, H.D. Wang, Y.X. Wu, Thin Solid Films, 488 (2005) 274-282.

[31] X.C. Zhang, B.S. Xu, H.D. Wang, Y.X. Wu, Mater. Des., 27 (2006) 308-315.

[32] X.C. Zhang, B.S. Xu, H.D. Wang, Y. Jiang, Y.X. Wu, Compos. Sci. Technol., 66 (2006) 2249-2256.

[33] M. Martena, D. Botto, P. Fino, S. Sabbadini, M.M. Gola, C. Badini, Eng. Fail. Anal., 13 (2006) 409-426.

[34] J.W. Hutchinson, J. Mech. Phys. Solids, 49 (2001) 1847-1864.

[35] S. Faulhaber, C. Mercer, M.W. Moon, J.W. Hutchinson, A.G. Evans, J. Mech. Phys. Solids, 54 (2006) 1004-1028.

[36] T. Qasim, M.B. Bush, X.Z. Hu, International Journal of Mechanical Sciences, 48 (2006) 244-248.

[37] Y.C. Zhou, T. Hashida, Inter. J. Solids Struct., 38 (2001) 4235-4264.

[38] W.G. Mao, Y.C. Zhou, L. Yang, X.H. Yu, Mech. Mater., 38 (2006) 1118-1127.

[39] J.M. Gere, S.P. Timoshenko, Mechanics of Materials, Chapman and Hall Inc, London, 1991.

[40] J. Cheng, E.H. Jordan, B. Barber, M. Gell, Acta Mater., 46 (1998) 5839-5850.

[41] W.Y. Lee, D.P. Stinton, C.C. Berndt, F. Erdogan, Y.-D. Lee, Z. Mutasim, J. Am. Ceram. Soc., 79 (1996) 3003-3012.

[42] Y. Ootao, Y. Tanigawa, O. Ishimaru, J. Therm. Stresses, 23 (2000) 257-271.

[43] S. Rangaraj, M. Kokini, Acta Mater., 51 (2003) 251-267.

[44] H.A. Bahr, H. Balke, T. Fett, I. Hofinger, G. Kirchhoff, D. Munz, A. Neubrand, A.S. Semenov, H.J. Weiss, Y.Y. Yang, Mater. Sci. Eng. A, 362 (2003) 2-16.

[45] S. Sharafat, A. Kobayashi, Y. Chen, N.M. Ghoniem, Vacuum, 65 (2002) 415-425.

[46] J.H. Kim, M.C. Kim, C.G. Park, Surf. Coat. Tech., 168 (2003) 275-280. 
[47] S. Rangaraj, K. Kokini, Journal of Engineering Materials and Technology, Transactions of the ASME, 126 (2004) 103-115.

[48] V. Teixeira, Surf. Coat. Tech., 146-147 (2001) 79-84.

[49] O. Kesler, J. Matejicek, S. Sampath, S. Suresh, T. Gnaeupel-Herold, P.C. Brand, H.J. Prask, Mater. Sci. Eng. A, 257 (1998) 215-224.

[50] A.N. Khan, J. Lu, H. Liao, Surf. Coat. Tech., 168 (2003) 291-299. 


\section{Figure captions}

Fig. 1. Schematic of three types of TBCs with cylindrical geometry based on the different positions of coating: (a) Type A1, (b) Type A2, and (c) Type A3.

Fig. 2. Schematic of the analytical model of substrate deformation on cooling, where three configurations are (a) original (stress free), (b) middle (no residual stress) and (c) final (residual stress), respectively.

Fig. 3. Effect of substrate curvature radius on the distribution of residual stress in type A1 TBCs: (a) radial stress and (b) hoop stress.

Fig. 4. Effect of substrate curvature radius on the distribution of residual stress in type A2 TBCs: (a) radial stress and (b) hoop stress.

Fig. 5. Effect of substrate curvature radius on the distribution of residual stress in type A3 TBCs: (a) radial stress and (b) hoop stress.

Fig. 6. The distribution of residual stress in TGO as a function of substrate curvature radius: (a) radial stress and (b) hoop stress.

Fig. 7. Effect of deposition temperature on the distribution of residual stress in type A1 TBCs: (a) radial stress and (b) hoop stress.

Fig. 8. Effect of deposition temperature on the distribution of residual stress in type A2 TBCs: (a) radial stress and (b) hoop stress.

Fig. 9. Effect of deposition temperature on the distribution of residual stress in type A3 TBCs: (a) radial stress and (b) hoop stress.

Fig. 10. The distribution of residual stress in TGO close to the coating/TGO interface as a function of deposition temperature: (a) radial stress and (b) hoop stress.

Fig. 11. Effect of coating thickness on the distribution of residual stress in type A1 TBCs: (a) radial stress and (b) hoop stress.

Fig. 12. Effect of coating thickness on the distribution of residual stress in type A2 TBCs: (a) 
radial stress and (b) hoop stress.

Fig. 13. Effect of coating thickness on the distribution of residual stress in type A3 TBCs: (a) radial stress and (b) hoop stress.

Fig. 14. Effect of coating thickness on the residual stress in TGO close to the coating/TGO interface: (a) radial stress and (b) hoop stress. 

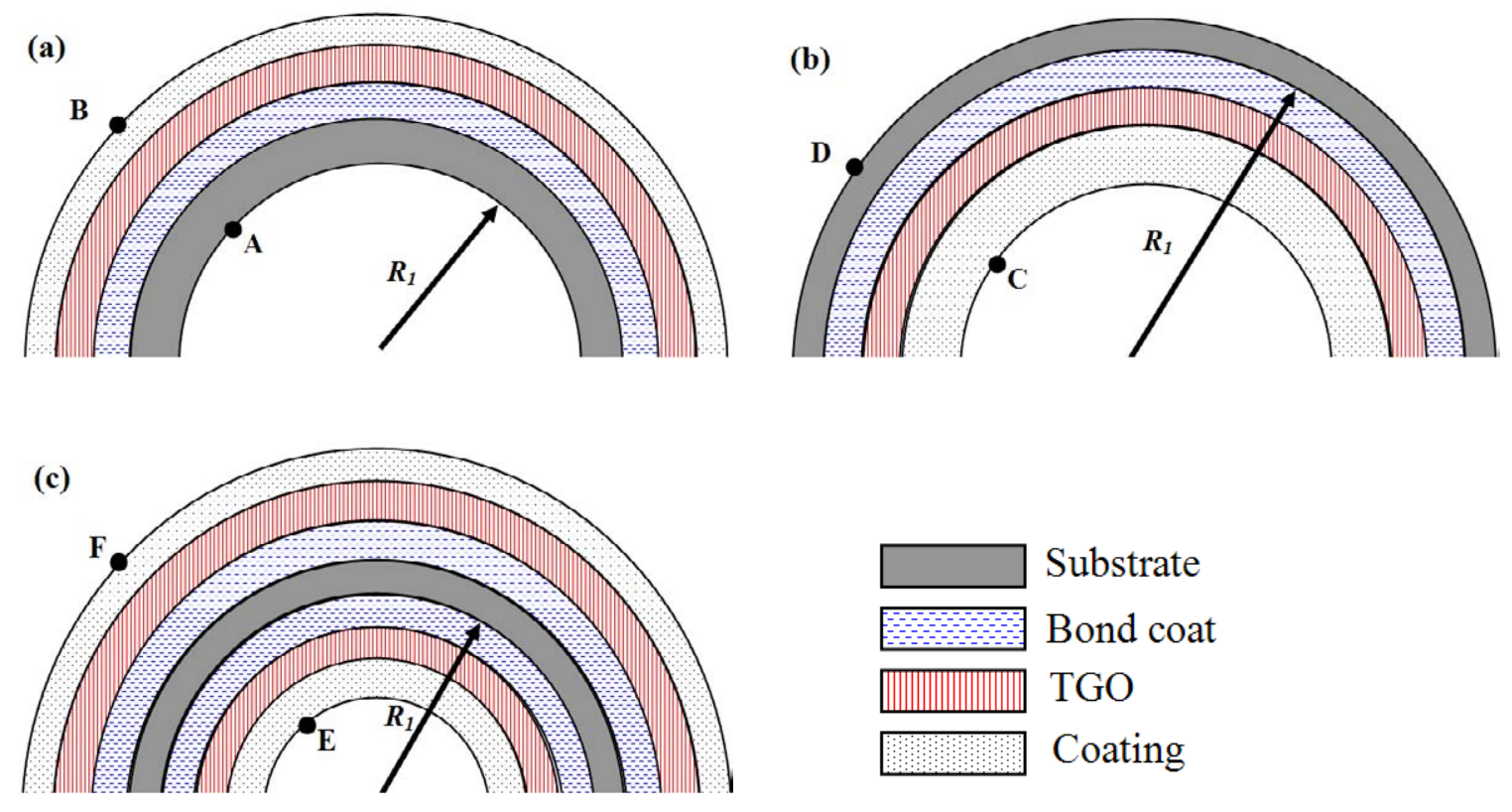

Fig. 1 


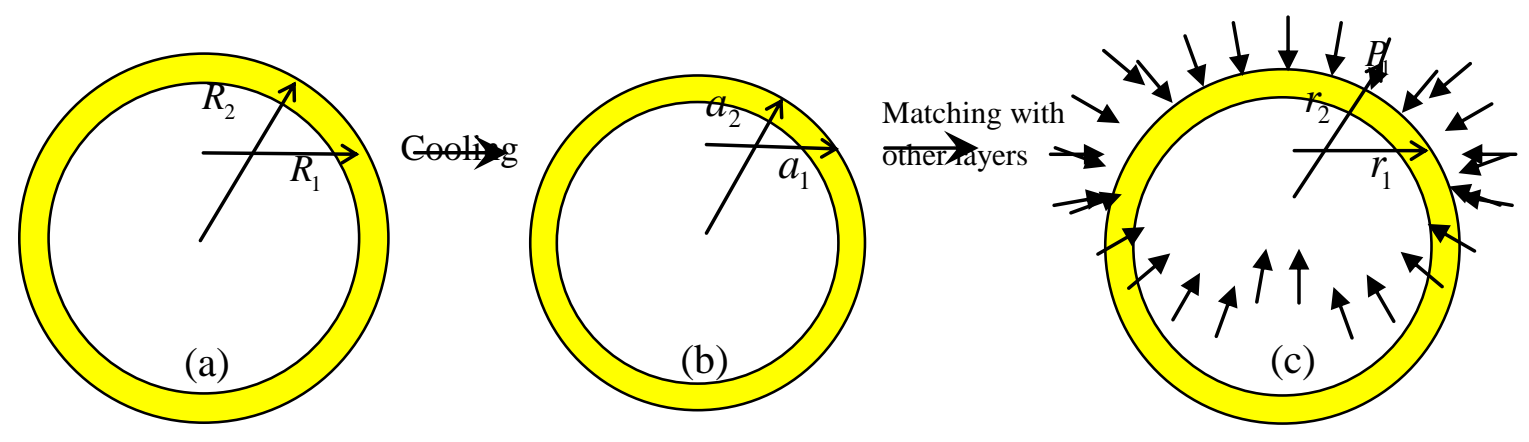

Fig. 2 

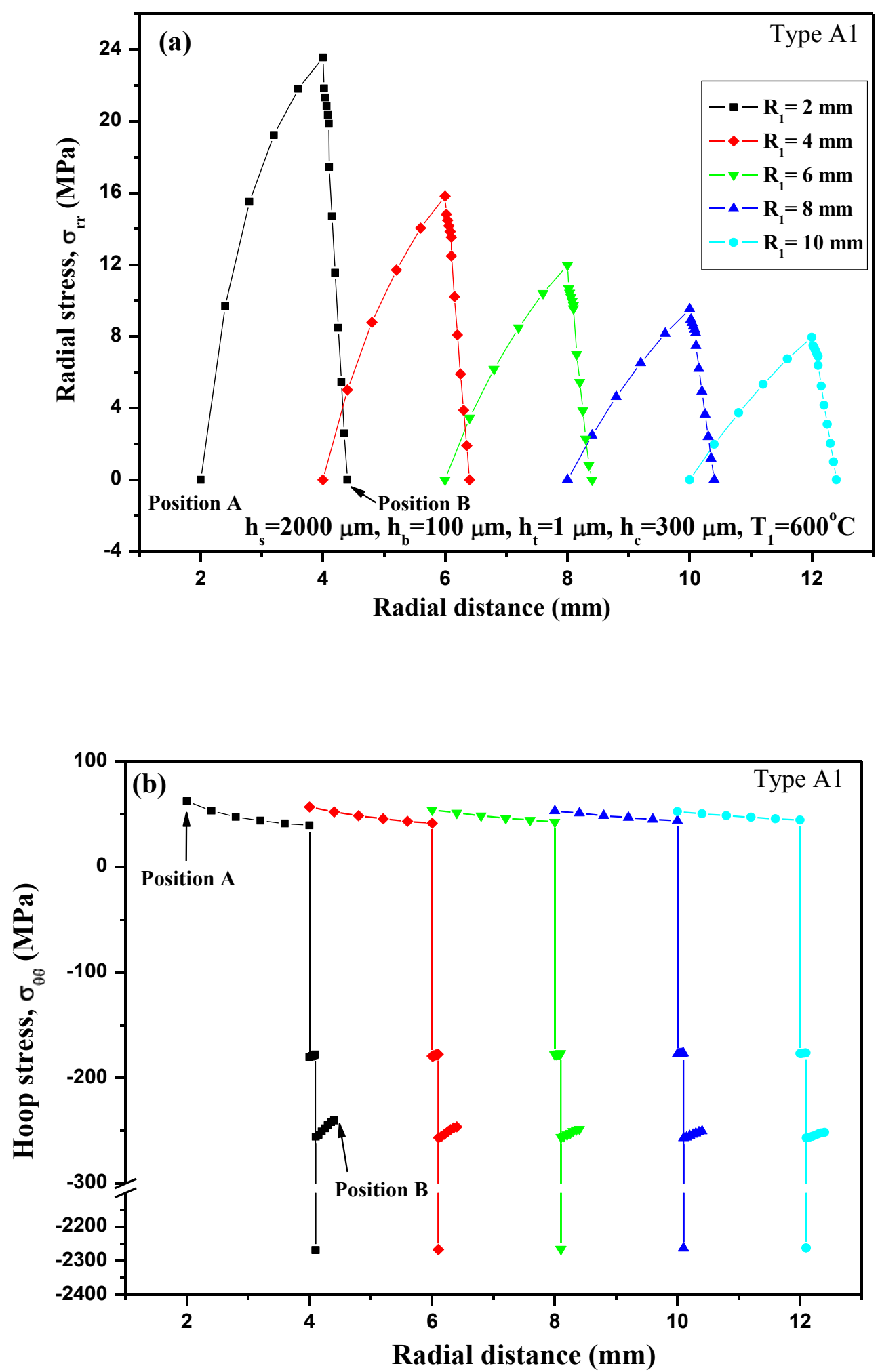

Fig. 3. 

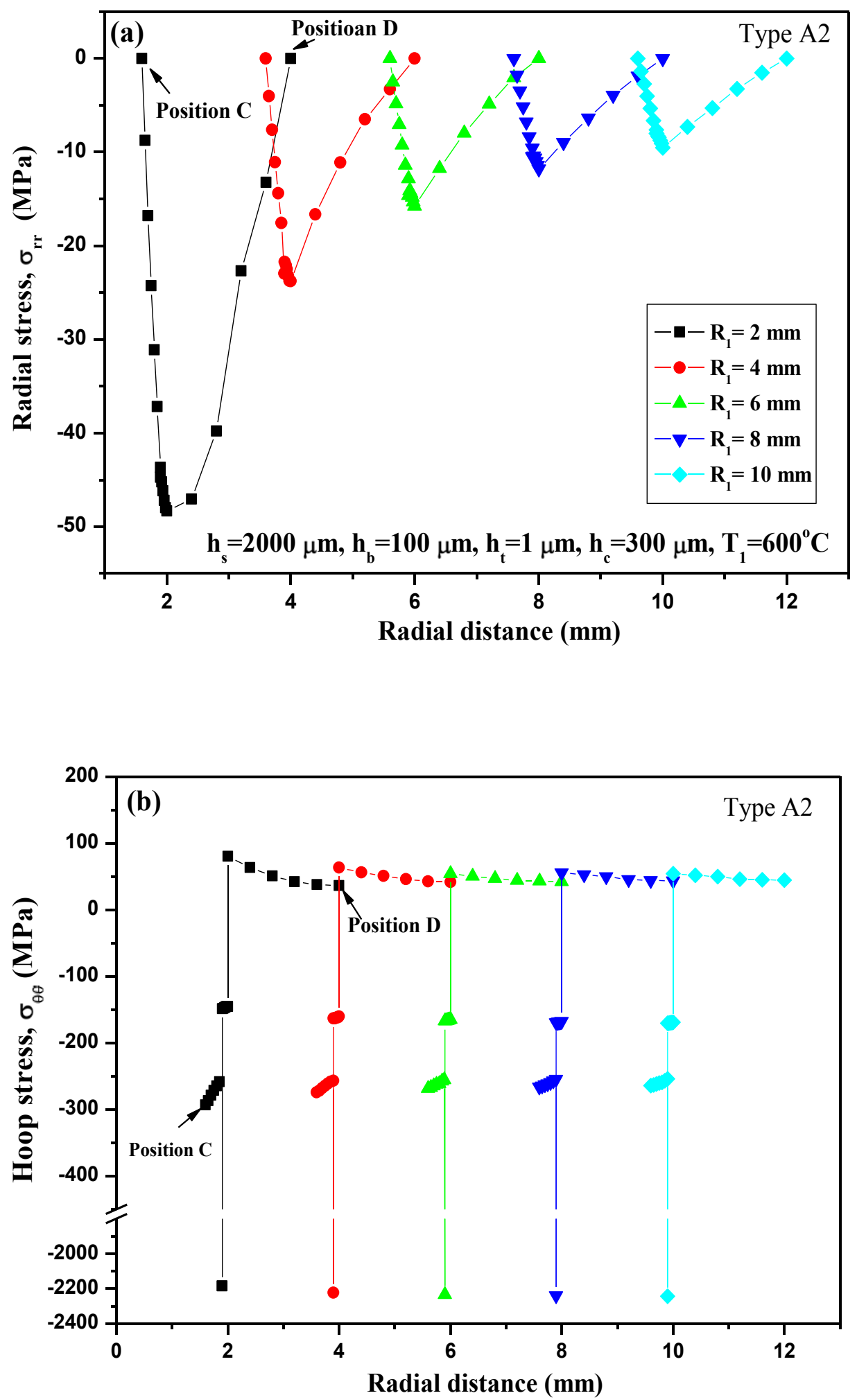

Fig. 4. 

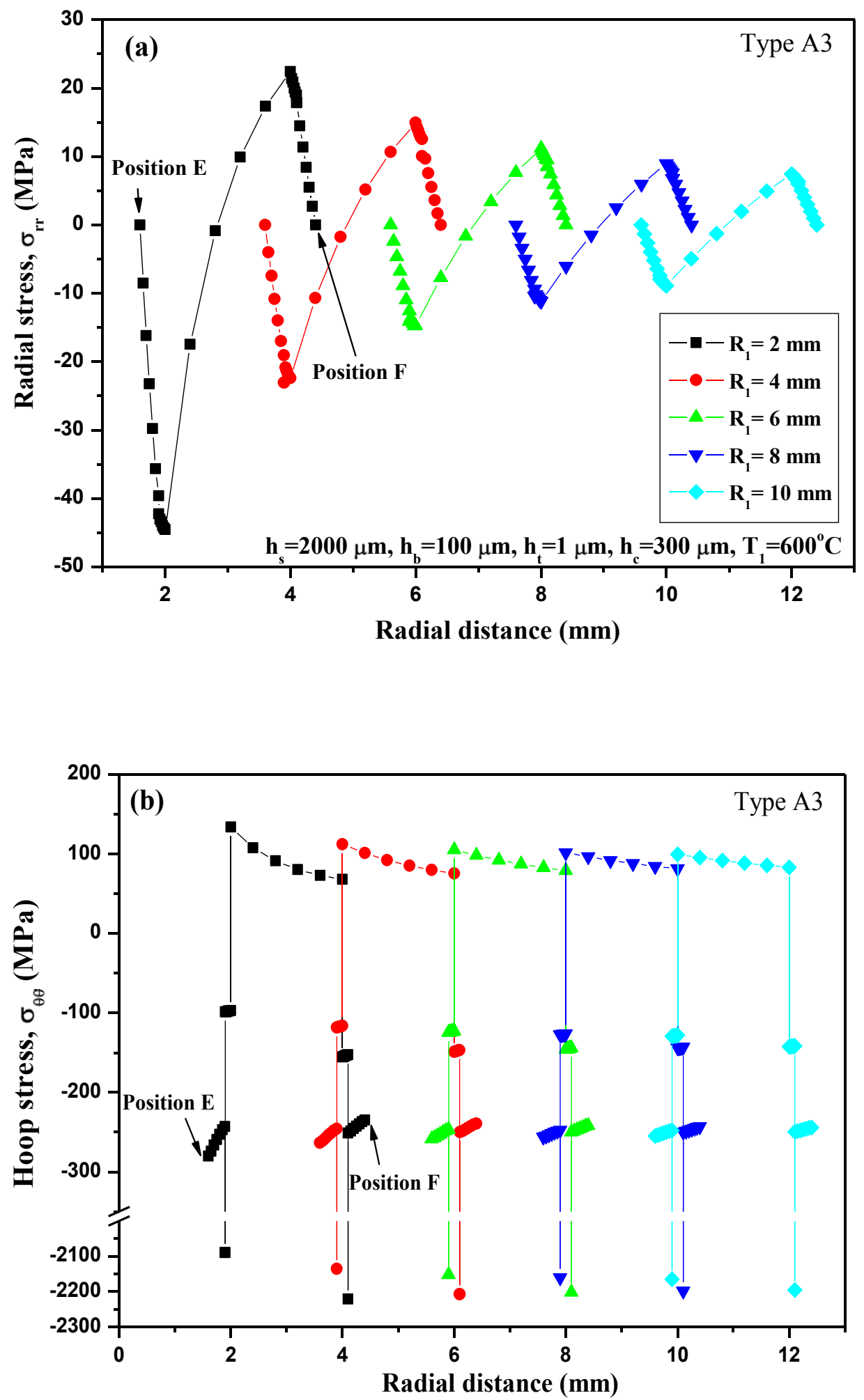

Fig. 5. 

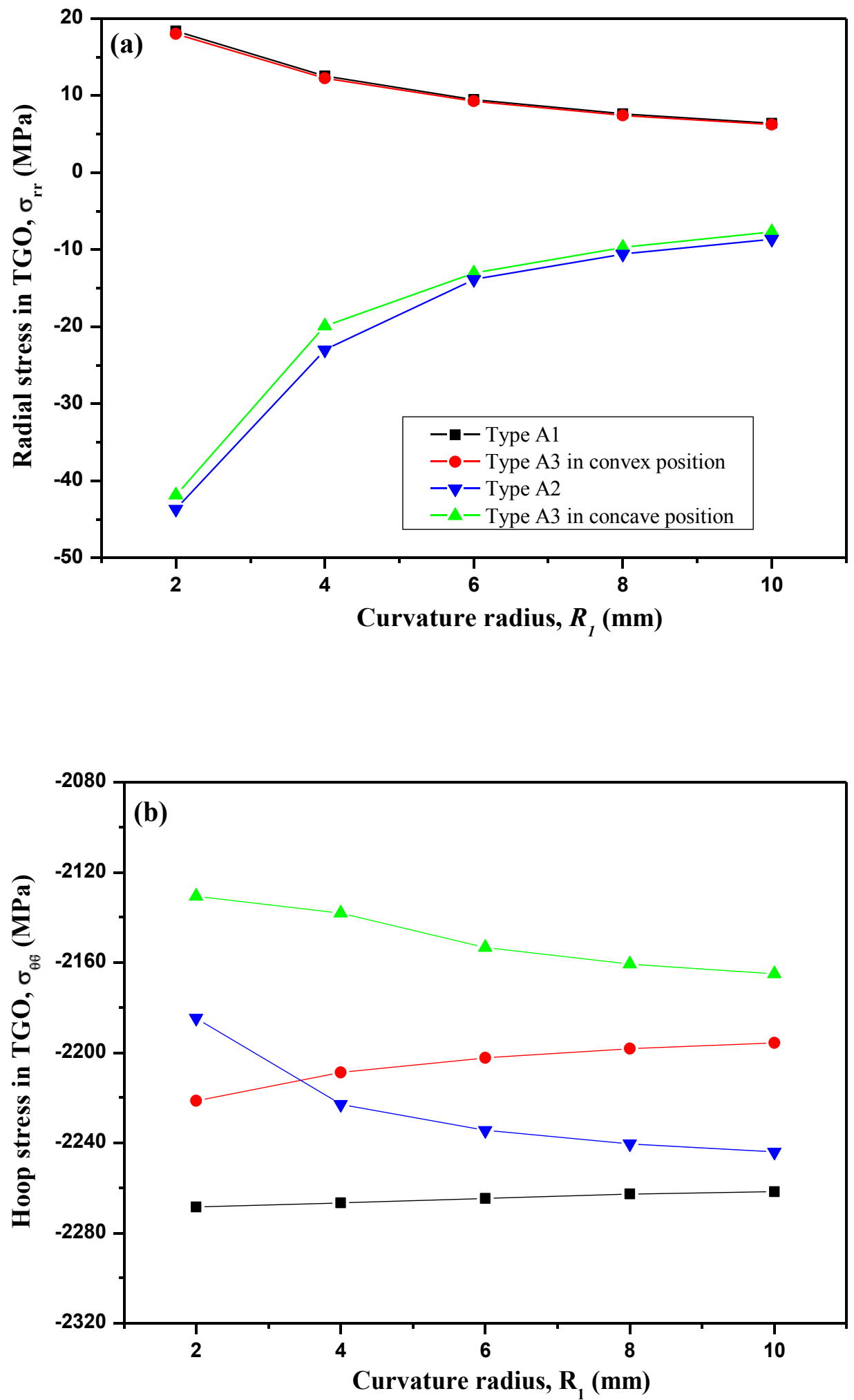

Fig. 6. 

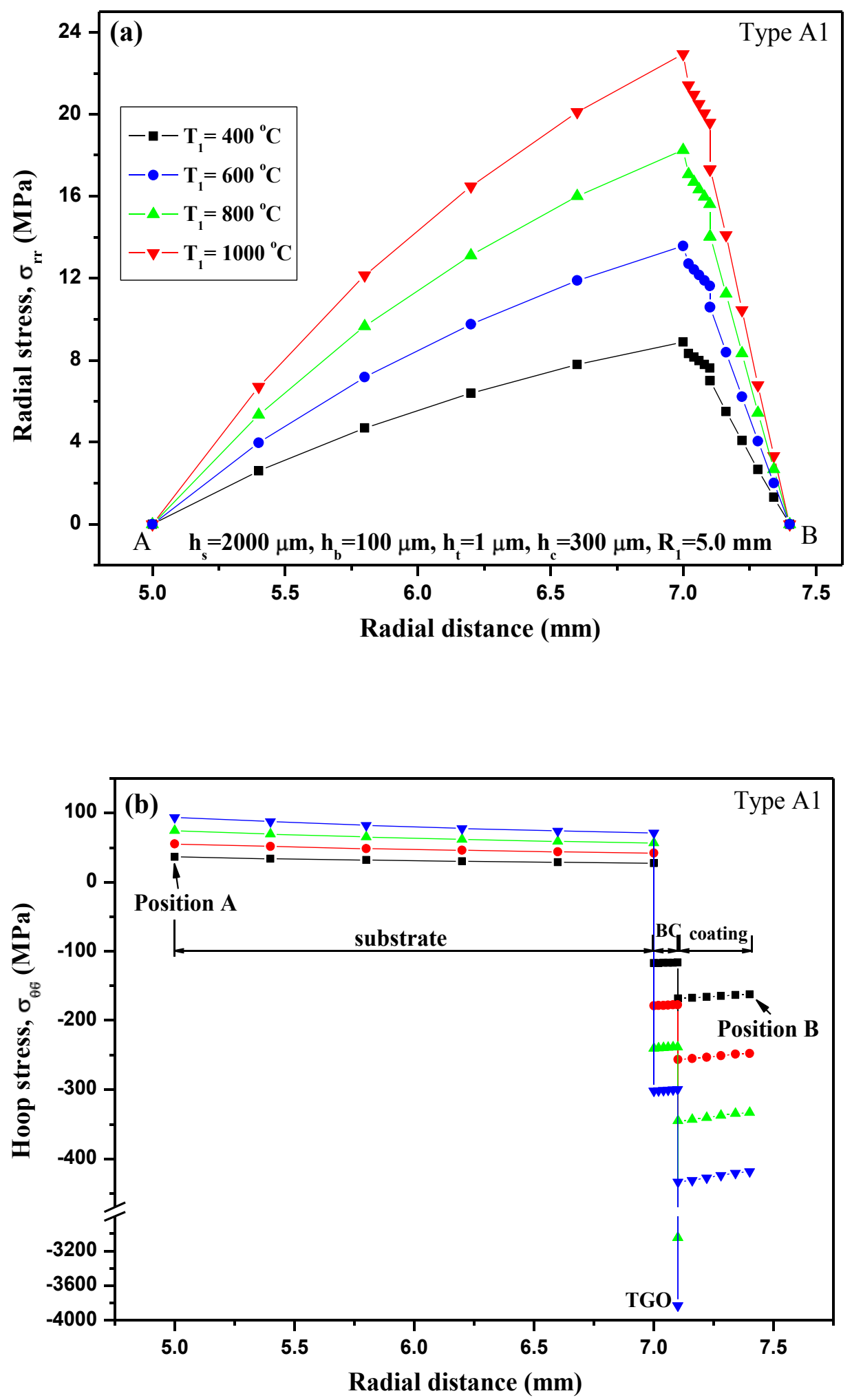

Fig.7. 

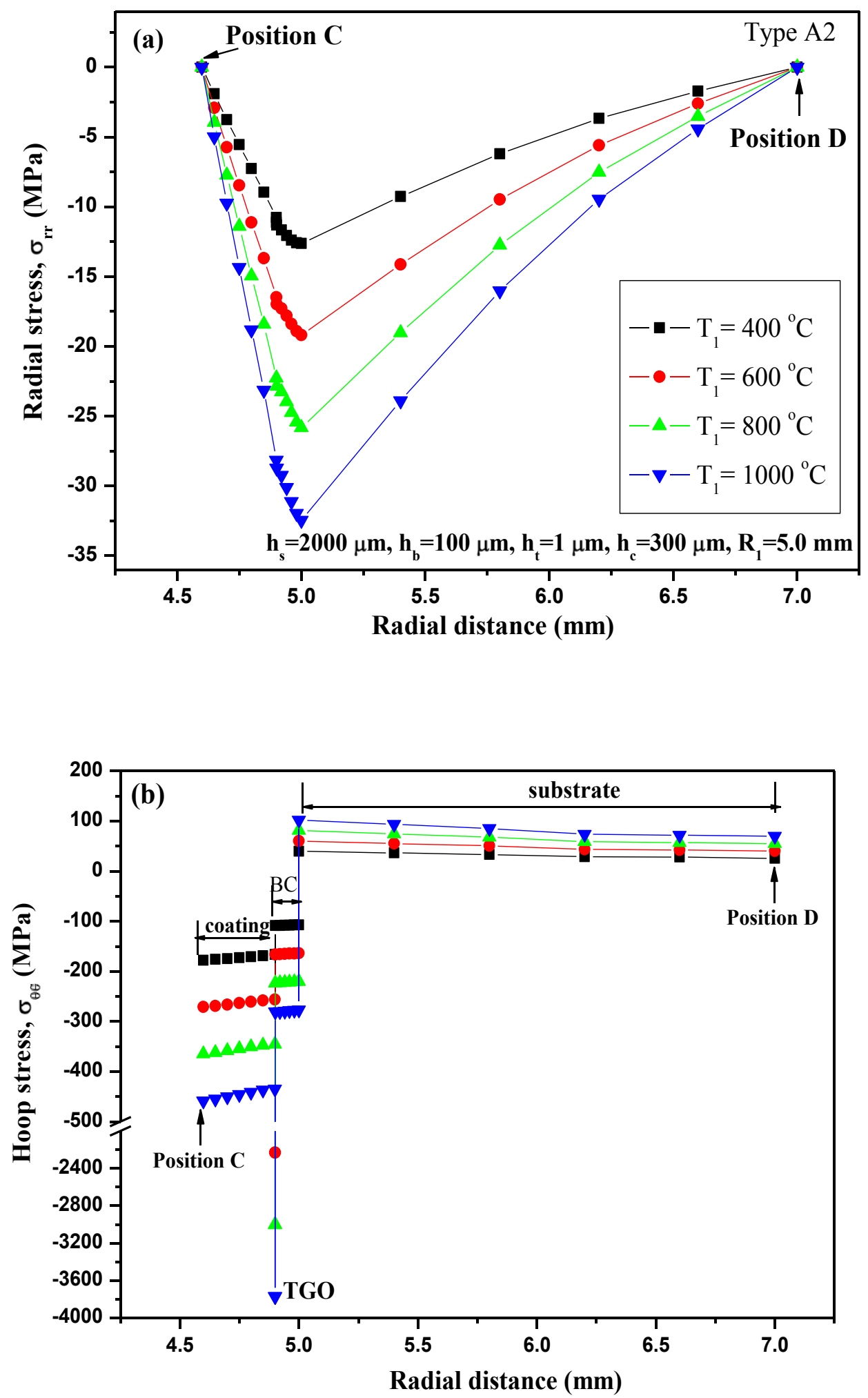

Fig. 8 

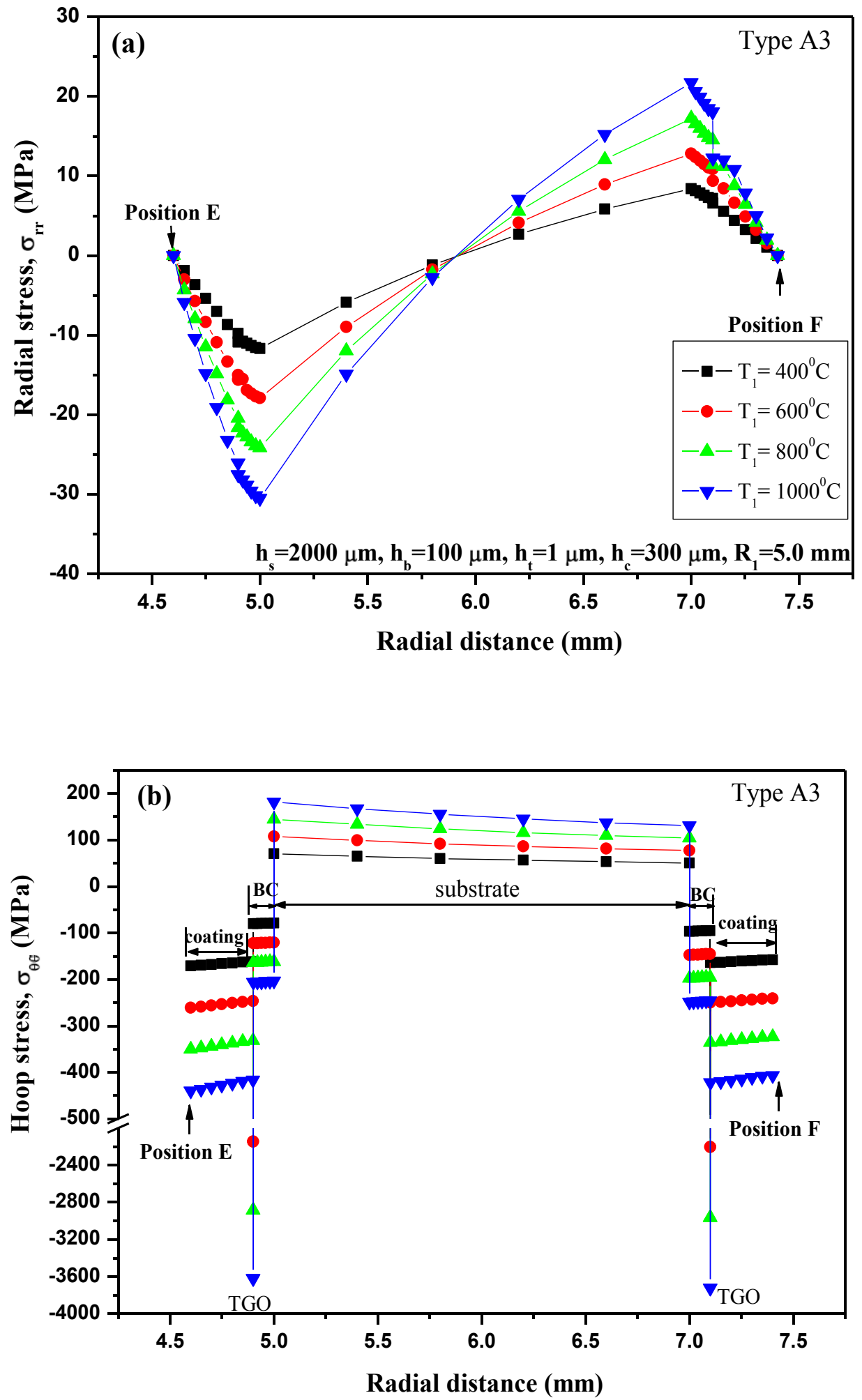

Fig.9 

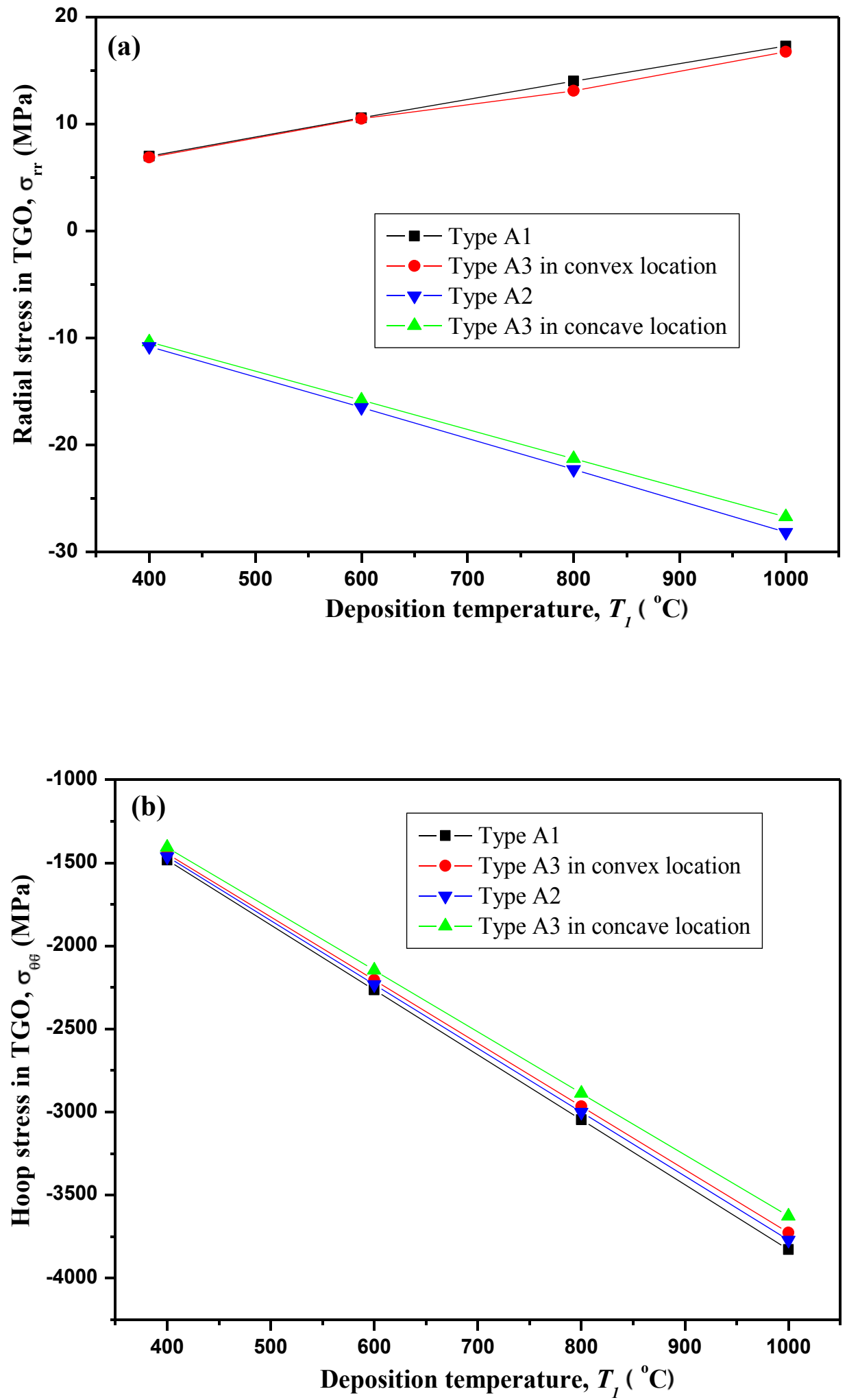

Fig. 10 

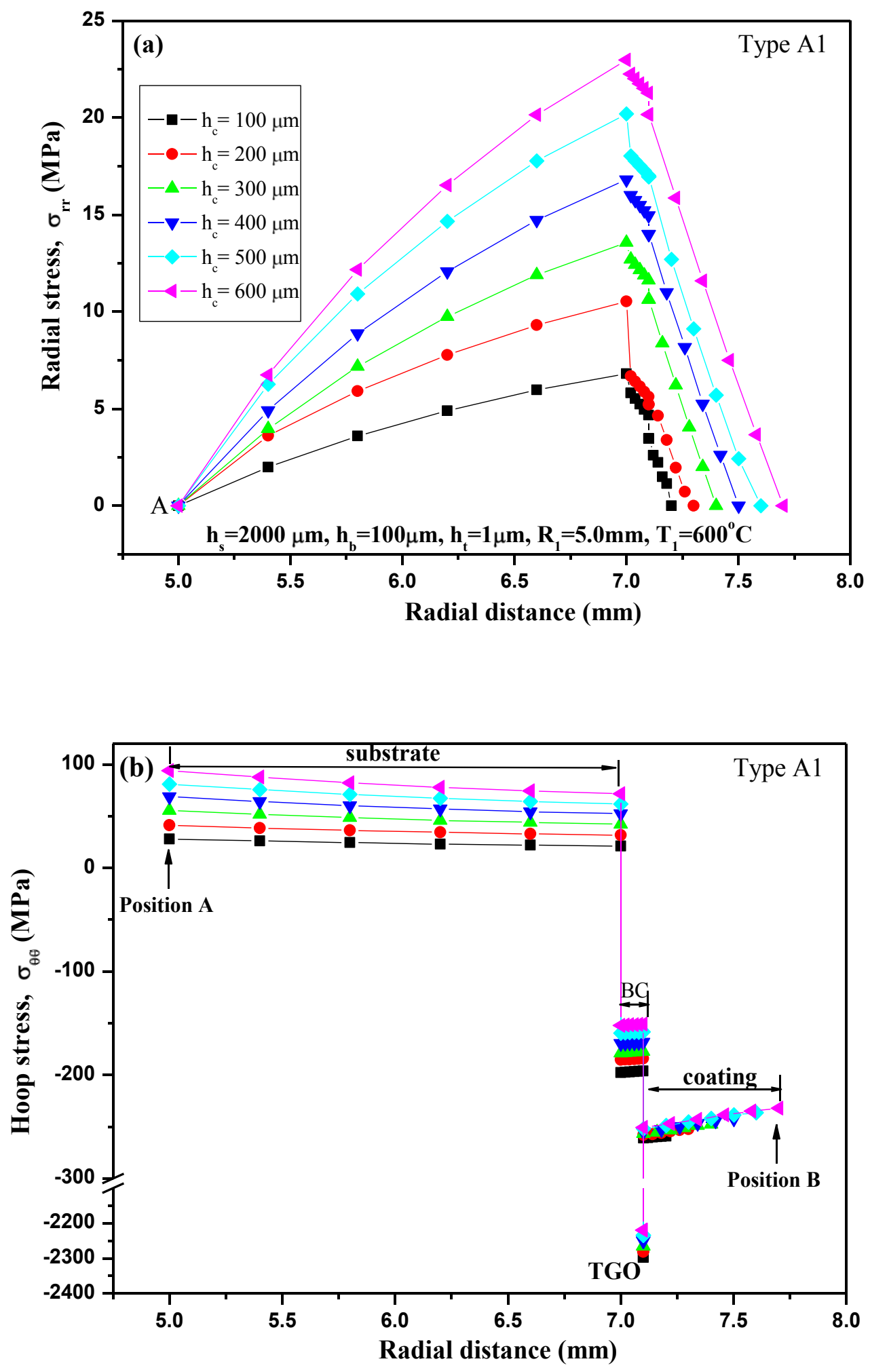

Fig. 11 

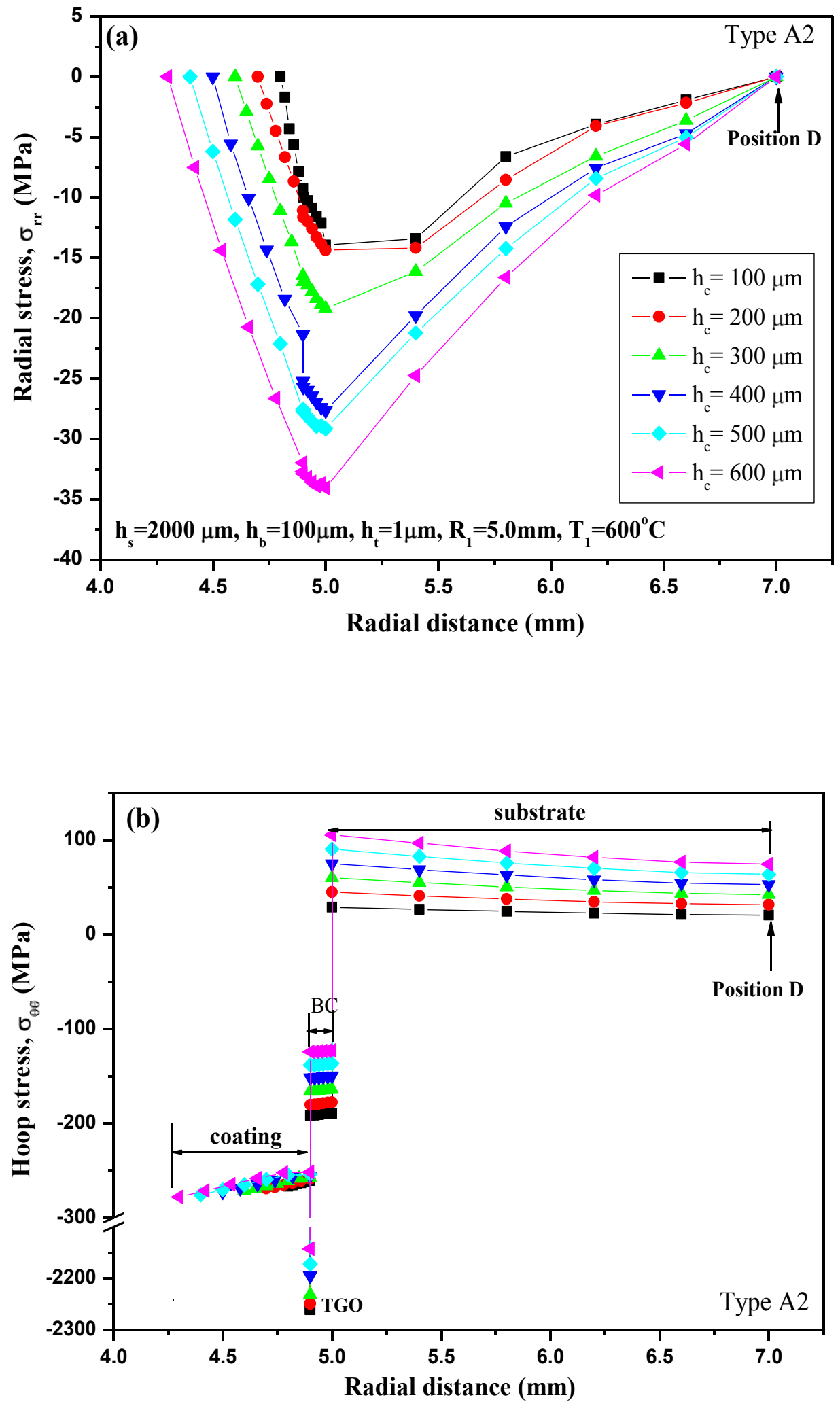

Fig. 12 

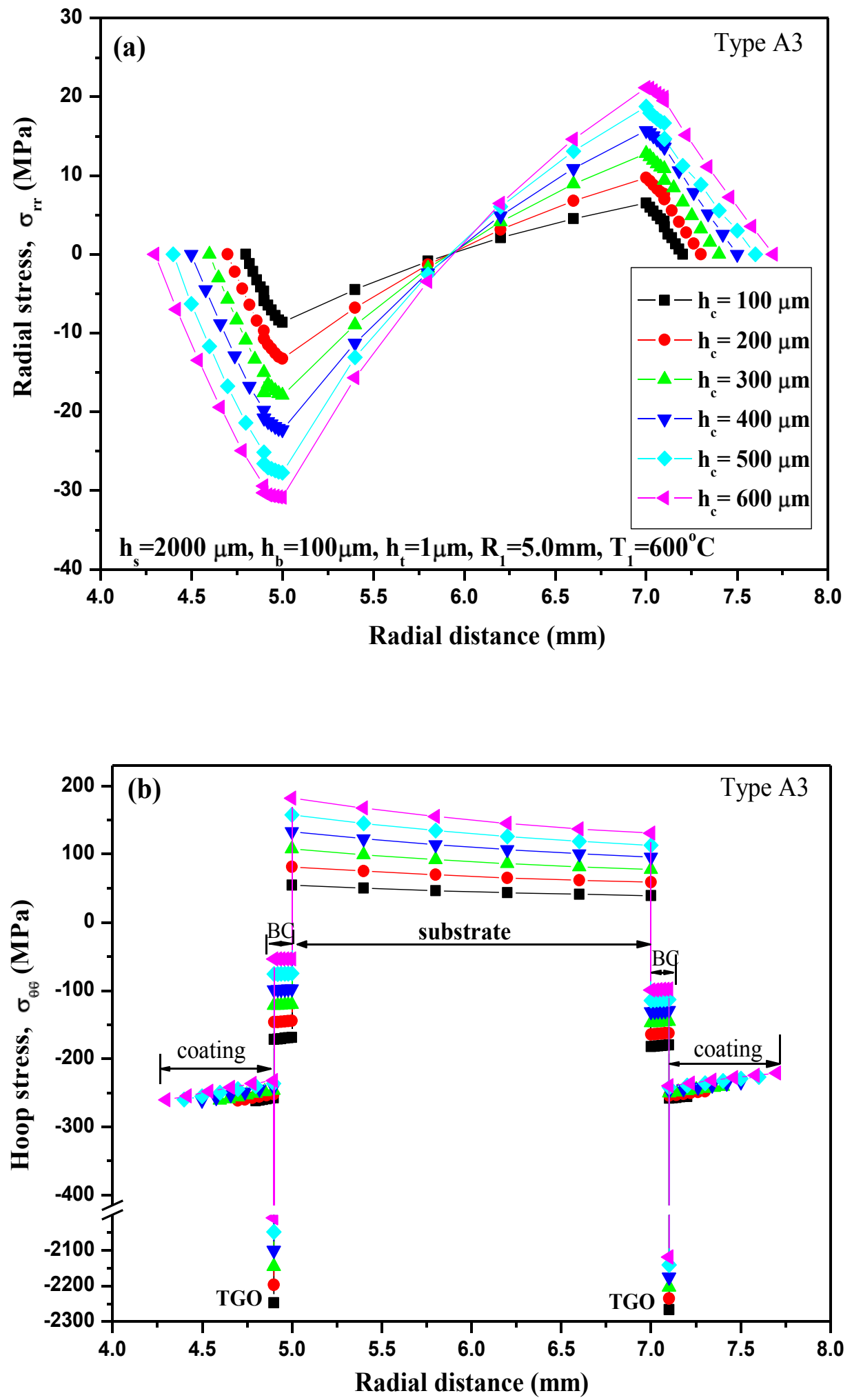

Fig.13 

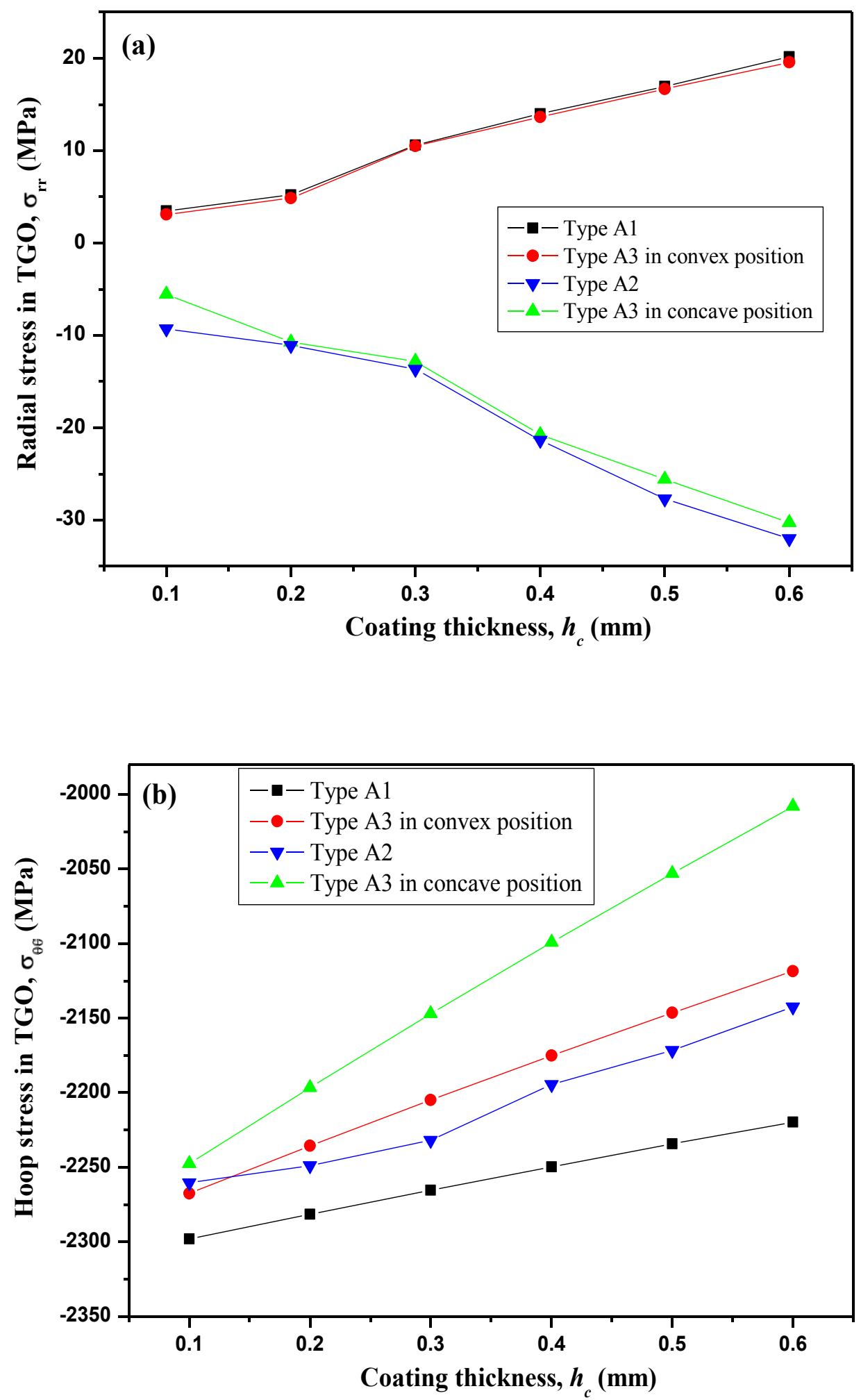

Fig.14 
Table 1. Material properties of the TBC system used in calculations [40], where 8YSZ refers to 8 wt. $\% \mathrm{Y}_{2} \mathrm{O}_{3}$ stabilized $\mathrm{ZrO}_{2}$.

\begin{tabular}{ccccc}
\hline Properties & 8 YSZ & TGO & Bond coat & Substrate \\
\hline$E(\mathrm{GPa})$ & 48 & 400 & 200 & 220 \\
$\mu$ & 0.10 & 0.23 & 0.30 & 0.31 \\
$\alpha\left(10^{-6} /{ }^{\circ} \mathrm{C}\right)$ & 9.0 & 8.0 & 13.6 & 14.8 \\
\hline
\end{tabular}


The coating position strongly influences the distribution of residual stress in TBCs.

Substrate curvature plays an important role in the evolution of residual stress.

The deposition temperature and coating thickness should be as small as possible. 